\title{
Surgical outcomes of borderline breast lesions detected by needle biopsy in a breast screening program
}

\author{
Karen M Flegg ${ }^{1 *}$, Jeffrey J Flaherty ${ }^{1}$, Anne M Bicknell ${ }^{2}$, Sanjiv Jain ${ }^{3}$
}

\begin{abstract}
Background: The Australian Capital Territory and South East New South Wales branch of BreastScreen Australia (BreastScreen ACT\&SENSW) performs over 20,000 screening mammograms annually. This study describes the outcome of surgical biopsies of the breast performed as a result of a borderline lesion being identified after screening mammography and subsequent workup.

A secondary aim was to identify any parameters, such as a family history of breast cancer, or radiological findings that may indicate which borderline lesions are likely to be upgraded to malignancy after surgery.

Methods: From a period of just over eight years, all patients of BreastScreen ACT\&SENSW who were diagnosed with a borderline breast lesion were identified. These women had undergone needle biopsy in Breastscreen ACT\&SENSW and either atypical ductal hyperplasia (ADH), flat epithelial atypia (FEA), atypical lobular hyperplasia $(\mathrm{ALH})$, radial scar/complex sclerosing lesion, papillary lesion, mucocoele-like lesion (MLL) or lobular carcinoma in situ (LCIS) was found. Final outcomes for each type of borderline lesion after referral for surgical biopsy were recorded and analysed. Results of the surgical biopsy were compared to the type of needle biopsy and its result, radiological findings and family history status.

Results: Of the 94 surgical biopsies performed due to the presence of a borderline breast lesion, 20\% showed benign pathology, 55\% remained as borderline lesions, 17\% showed non-invasive malignancy and $7 \%$ showed invasive malignancy. VALCS biopsy was the most common needle biopsy method used to identify the lesions in this study (76\%). Malignant outcomes resulted from $24 \%$ of the surgical biopsies, with the most common malignant lesion being non-comedo ductal carcinoma in situ (DCIS). The most common borderline lesion for which women underwent surgical biopsy was ADH (38\%). Of these women, 22\% were confirmed as ADH on surgical biopsy and $47 \%$ with a malignancy.

Conclusions: Further research is required to determine whether characteristics of the mammographic lesion (particularly calcification patterns), the area targeted for biopsy and number of core samples retrieved, can indicate a closer correlation with eventual pathology. This study identified no findings in the diagnostic assessment that could exclude women with borderline lesions from surgical biopsy.
\end{abstract}

\section{Background}

The Australian Capital Territory and South East New South Wales (BreastScreen ACT\&SENSW) branch of BreastScreen Australia performs over 20,000 screening mammograms annually [1]. The program specifically targets women aged 50 to 69 years and also allows

\footnotetext{
* Correspondence: karen.flegg@anu.edu.au

1 Australian National University, Medical School. The Canberra Hospital,

Building 4, PO Box 11, Woden, ACT, 2606, Australia

Full list of author information is available at the end of the article
}

access to women from $40-49$ and 70 and over. Screening consists of two mammography views of each breast, a mediolateral oblique and a cranio-caudal view. Films are double read by two radiologists operating independently and if an abnormality is detected by mammography, patients are recalled for workup, often including fine needle biopsy (FNB) and/or a core needle biopsy (CNB) guided by ultrasound (14-16 gauge), or a vacuum assisted large core (11 gauge) stereotactic (VALCS) biopsy.

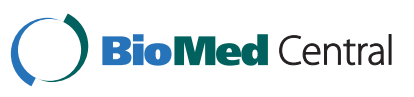


There are a number of lesions which, when detected using a needle biopsy cause diagnostic uncertainty. These so called borderline breast lesions, are lesions which may coexist with breast malignancy, or lie on a spectrum of pathological entities which are difficult to distinguish from malignant lesions [2,3]. The borderline lesions recognised in this study are ADH [4], LCIS, ALH [5], papillary lesions, FEA [6], MLL [7] and complex sclerosing lesions/radial scars [8]. Currently, at BreastScreen ACT\&SENSW, if FNB or CNB demonstrate borderline lesions the patient is referred for a diagnostic surgical biopsy to exclude the possibility of a closely situated carcinoma.

Borderline lesions are a relatively rare occurrence and for this reason there is little data in the literature from which pathologists, breast physicians and surgeons can construct management plans with an evidence based focus [2]. The primary aim of this study was to describe how many malignancies are revealed when surgical biopsy is performed due to the presence of a borderline lesion on needle biopsy in an Australian breast screening program. The secondary aim was to identify any parameters, such as a family history of breast cancer, or findings during radiological assessment that may indicate which lesions are likely to be upgraded to malignancy. These findings could result in recommendations that would lead to a reduction in the number of women that undergo a purely diagnostic surgical biopsy.

\section{Methods}

During the period August 1998 to November 2006, a total of 167 women underwent a diagnostic open surgical biopsy as a result of a screen detected mammographic abnormality at BreastScreen ACT\&SENSW. Patients were selected for inclusion in this study if they were referred for surgical biopsy because their FNB or CNB showed a borderline lesion, namely, ADH, FEA, $\mathrm{ALH}$, radial scar/complex sclerosing lesion, papillary lesion, MLL or LCIS. This resulted in a total of 94 women with borderline lesions being included in this study.

The medical records of the included women were examined to determine the results of their mammogram, ultrasound, and family history status. Family history status was established using the three categories of risk used by the National Breast and Ovarian Cancer Centre (NBOCC) [9]. Results of their surgical biopsy were compared to their needle biopsy result and the type of needle biopsy that was done. All pathology was reviewed by two independent pathologists experienced in breast pathology, in line with the normal protocol at BreastScreen ACT\&SENSW.

Fibroadenomas/phyllodes lesions were also examined but for the purposes of this study, were not included as borderline lesions. At BreastScreen ACT\&SENSW fibroepithelial lesions are excised if the imaging suggests a suspicious pattern or the distinction cannot be made between a fibroadenoma and a phyllodes tumour.

Ethics approval was given by the human research ethics committee of Australian Capital Territory (ACT) Health and a sub-committee representing the Australian National University (ANU) Medical School on behalf of the ANU human research ethics committee.

\section{Results}

During the study period of just over eight years, there were 94 borderline lesions identified on needle biopsy that were recommended for a surgical biopsy. Vacuum assisted large core stereotactic guided core needle (VALCS) biopsy was the most common needle biopsy method used to identify the lesions in this study (76\%).

Malignant outcomes were revealed in 24\% $(n=23)$ of the surgical biopsies, with the most common malignant lesion being non-comedo ductal carcinoma in situ (DCIS). (Table 1) Of the borderline lesions identified by VALCS biopsy, malignancy was found in $31 \%$ of cases. None of the lesions identified using US guided CNB showed malignancy on open biopsy. When a borderline lesion was diagnosed on FNB only, then open biopsy showed a malignant lesion in $10 \%(n=1)$ of cases.

The most common borderline lesion for which women underwent surgical biopsy was ADH (38\%). Of these 36 women, $22 \%(n=8)$ were confirmed as ADH on surgical biopsy and $47 \%(\mathrm{n}=17)$ with a malignancy. The final pathology of the others originally thought to have ADH showed ductal hyperplasia with no atypia $(\mathrm{n}=4)$, ALH $(n=1)$, radial scar $(n=1)$, FEA $(n=2)$, fibrocystic change $(n=2)$ and benign scar tissue $(n=1)$.

All radial scars had a benign outcome after surgical biopsy, with $72 \%$ having no change to their diagnosis, while the remainder consisted of ADH $(n=1)$, fibrocystic change $(n=3)$ and papillary lesions $(n=1)$.

The radiographic abnormalities for which the women underwent a needle biopsy are shown in table 2. Needle biopsies performed for calcifications, stellate lesions and discrete opacities showed malignancy following surgical biopsy in $33 \%, 17 \%$ and $16 \%$ of cases respectively. The radiological findings are shown with the pre- and post surgical diagnosis to highlight the information at different stages of the diagnostic triple test. Its is also useful because although the definitive diagnosis may change from a borderline to malignant lesion, the borderline lesion was still an identified pathological process with associated mammographic findings.

Only one woman, of the 23 with malignant diagnoses, was in a high risk group based on family history (ADH on needle biopsy and eventually diagnosed with a tubular carcinoma), five women were in the moderate risk 
Table 1 Needle biopsy diagnosis* compared to results of surgical biopsy

\begin{tabular}{|c|c|c|c|c|}
\hline \multirow[t]{2}{*}{ Needle Biopsy Diagnosis* } & \multirow[t]{2}{*}{$\mathrm{N}=$} & \multicolumn{3}{|c|}{ Surgical Biopsy Diagnosis } \\
\hline & & Non-malignant $\neq$ & DCIS & Invasive Malignancy \\
\hline $\mathrm{ADH}$ & 36 & $19(53 \%) \S$ & $13(36 \%)$ & $4(11 \%)$ \\
\hline $\mathrm{ALH}$ & 4 & $4(100 \%)$ & & \\
\hline LCIS & 5 & $3(60 \%)$ & $1(20 \%)$ & $1(20 \%)$ \\
\hline Radial Scar + & 18 & $18(100 \%) \|$ & & \\
\hline FEA & 5 & $3(60 \%)$ & $1(20 \%)$ & $1(20 \%)$ \\
\hline MLL & 3 & $3(100 \%) 9$ & & \\
\hline Papillary lesion & $23 * *$ & $21(91 \%)$ & $1(4 \%)+\dagger$ & $1(4 \%) \neq \neq$ \\
\hline Total & 94 & $71(76 \%)$ & $16(17 \%)$ & $7(7 \%)$ \\
\hline
\end{tabular}

* biopsy type = Vacuum assisted large core stereotactic guided core needle biopsy (VALCS) unless stated otherwise

† Radial Scar represents both radial scars and complex sclerosing lesions.

₹ Non-Malignant lesions include borderline lesions and benign lesions (ductal hyperplasia with no atypia, sclerosing adenosis, fibroadenoma, fibrocystic change and scar tissue).

$\S$ biopsy type on one lesion by Ultrasound guided core needle biopsy (USCNB)

$\|$ biopsy type on four lesions by USCNB

I biopsy type on one lesion USCNB and on two lesions Fine needle biopsy (FNB)

** biopsy type on seven lesions USCNB and on eight lesions FNB

†† biopsy type VALCS only

\# biopsy type FNB only

$\mathrm{ADH}=$ Atypical ductal hyperplasia; $\mathrm{ALH}=$ Atypical lobular hyperplasia; $\mathrm{FEA}=$ Flat epithelial atypia; $\mathrm{LCIS}=$ Lobular carcinoma in situ; $\mathrm{MLL}=\mathrm{Mucocoele-like}$ lesions;

Table 2 Radiological findings for pre- and post- surgical diagnosis of borderline lesions

\begin{tabular}{|c|c|c|c|c|c|c|c|}
\hline \multirow[t]{2}{*}{ Diagnosis } & \multicolumn{7}{|c|}{ Mammogram Findings $n=(\%)$} \\
\hline & Calcification & $\begin{array}{l}\text { Stellate } \\
\text { lesion }\end{array}$ & $\begin{array}{l}\text { Discrete } \\
\text { opacity }\end{array}$ & $\begin{array}{l}\text { Multiple } \\
\text { opacities }\end{array}$ & $\begin{array}{l}\text { Architectural } \\
\text { distortion }\end{array}$ & $\begin{array}{c}\text { Non specific } \\
\text { density }\end{array}$ & Total \\
\hline Total & $51(54 \%)$ & $18(19 \%)$ & $19(20 \%)$ & $1(1 \%)$ & $4(4 \%)$ & $1(1 \%)$ & 94 \\
\hline \multicolumn{8}{|c|}{ Mammogram findings by NEEDLE BIOPSY diagnosis } \\
\hline $\mathrm{ADH}$ & $33(92 \%)$ & $2(6 \%)$ & & & $1(3 \%)$ & & 36 \\
\hline $\mathrm{ALH}$ & $3(75 \%)$ & & & & $1(25 \%)$ & & 4 \\
\hline$\overline{\mathrm{LCIS}}$ & $4(80 \%)$ & & $1(20 \%)$ & & & & 5 \\
\hline Radial Scar* & $2(11 \%)$ & $14(78 \%)$ & & & $2(11 \%)$ & & 18 \\
\hline FEA & $4(80 \%)$ & $1(20 \%)$ & & & & & 5 \\
\hline MLL & & & $3(100 \%)$ & & & & 3 \\
\hline Papillary Lesion & $5(22 \%)$ & $1(4 \%)$ & $15(65 \%)$ & $1(4 \%)$ & & $1(4 \%)$ & 23 \\
\hline \multicolumn{8}{|c|}{ Mammogram findings by SURGICAL BIOPSY diagnosis } \\
\hline$\overline{\mathrm{ADH}}$ & $10(91 \%)$ & $1(9 \%)$ & & & & & 11 \\
\hline $\mathrm{ALH}$ & $4(100 \%)$ & & & & & & 4 \\
\hline LCIS & $1(100 \%)$ & & & & & & 1 \\
\hline Radial Scar* & & $12(67 \%)$ & & $1(6 \%)$ & $4(22 \%)$ & $1(6 \%)$ & 18 \\
\hline FEA & $2(100 \%)$ & & & & & & 2 \\
\hline$\overline{M L L}$ & & & $2(100 \%)$ & & & & 2 \\
\hline Papillary Lesion & $2(14 \%)$ & $1(7 \%)$ & $11(79 \%)$ & & & & 14 \\
\hline $\begin{array}{l}\text { Other benign } \\
\text { dysplasia }^{\dagger}\end{array}$ & $15(79 \%)$ & $1(5 \%)$ & $3(16 \%)$ & & & & 19 \\
\hline DCIS & $13(81 \%)$ & $1(6 \%)$ & $2(13 \%)$ & & & & 16 \\
\hline Invasive Malignancy & $4(57 \%)$ & $2(29 \%)$ & $1(14 \%)$ & & & & 7 \\
\hline
\end{tabular}

* Radial Scar represents both radial scars and complex sclerosing lesions.

† Other benign dysplasia includes lesions such as ductal hyperplasia with no atypia $(n=8)$, sclerosing adenosis $(n=2)$, fibroadenoma ( $n=1)$, fibrocystic change $(n=7)$ and scar tissue $(n=1)$.

$\mathrm{ADH}$, Atypical ductal hyperplasia; ALH, Atypical lobular hyperplasia; FEA, Flat epithelial atypia; FNB, Fine needle biopsy; LCIS, Lobular carcinoma in situ; MLL, Mucocele-like lesions; US CNB, Ultrasound guided core needle biopsy; VALCS, Vacuum assisted large core stereotactic guided core needle biopsy. 
group and 17 had no increased risk compared to the general population.

Of women who had a surgical biopsy, 59\% had an ultrasound performed after the initial abnormality was detected by mammography. The ultrasound findings were extremely variable and hence the data is not shown. However, all patients who had a solid lesion designated as likely to be benign on the ultrasound $(\mathrm{n}=$ 10) were diagnosed with a non-malignant lesion after a surgical biopsy.

\section{Discussion}

The 'triple test' diagnostic process that involves a clinical examination, radiological assessment and a needle biopsy is $99.6 \%$ sensitive, and has $93 \%$ specificity for identifying a breast malignancy [10]. However, surgical biopsy is often required for complete assessment of borderline lesions. This study looked at the outcomes of all surgical biopsies performed due to the presence of borderline lesions on $\mathrm{CNB}$ or $\mathrm{FNB}$, during a period of just over eight years, at BreastScreen ACT\&SENSW. In this study $24 \%$ of women who underwent a surgical biopsy were found to have an invasive breast malignancy or DCIS which can be compared to reported malignancy rates for borderline lesions as high as $35 \%$ in nonscreening populations [3].

$\mathrm{ADH}$ was the most common lesion for which women were referred for a surgical biopsy and previous studies which were not limited to screening populations, report comparable rates of malignant diagnosis $(31-48 \%$ as compared with $47 \%$ in this study) after surgical excision of ADH with some smaller samples report rates ranging from $10-60 \%[3,4,11]$. The concerns with $\mathrm{ADH}$ are that it not only coexists with malignancy, it is a non-obligate precursor to breast cancer [4,11-15]. Moreover, it is difficult to distinguish ADH from a low grade DCIS and in sampling a lesion using $\mathrm{CNB}$, any $\mathrm{ADH}$ seen on histological assessment may represent only part of a lesion which also contains DCIS.

It is of interest that 11 of the ADH lesions identified at needle biopsy showed no ADH or malignant lesion on surgical biopsy. The explanation for this may be that the area of abnormality in these lesions was either completely excised during the needle biopsy procedure, or the sections of the surgical biopsy specimen examined by the pathologist may not have been sufficiently representative of the entire lesion.

Malignancy rates in the order of 30\% with FEA after surgical excision have been reported [16] and we found a similarly high rate of malignancy in the women with FEA (40\%). FEA lesions are excised because they have been shown to coexist with carcinoma and the atypia falls in a spectrum of pathology that encompasses ADH and DCIS $[6,17]$.
The lobular neoplasias, ALH and LCIS are less common and $17-44 \%$ are reported to be associated with malignancy $[5,8,14]$. In our study none of the women with ALH, but $40 \%$ of women with LCIS on needle biopsy had a malignancy. The presence of lobular neoplasia is a risk factor for the development of breast cancer in either breast [18]. If the sample size of our study were larger we might have expected rates of malignancy after excision of ALH lesions, to be closer to those published by others which ranged from 14-25\% [5,11,14]. The same studies report a malignant diagnosis of 25$33 \%$ of women initially diagnosed with LCIS $[5,11,14]$.

In this study none of the radial scar diagnoses at needle biopsy were shown to have a malignancy at surgery. Radial scars have previously been shown to have a significant rate (up to 25\%) of associated malignancy $[3,19]$. For this reason, even though this study showed no upgrade from the diagnosis of a radial scar to a malignancy we recommend that lesions designated as radial scar or a complex sclerosing lesion continue to be excised. Evidence also supports that it is an independent risk factor for breast cancer which warrants aggressive screening $[8,20,21]$.

Only three MLL were identified in the current study and none were associated with a malignant surgical specimen. One small study found malignancy in up to $30 \%$ of MLL, [7] however all of these were associated with ADH and would have been included in the ADH group in our study. Because, MLL are difficult to distinguish from mucinous carcinoma excision is still recommended [2].

It is reported that $14 \%$ of atypical papillomata and $23 \%$ of all papillary lesions are associated with either DCIS or papillary carcinoma $[3,8]$. ADH and lobular neoplasia are also known to commonly coexist with papillomas [22]. In our study $9 \%$ of papillary lesions were found to have a malignant surgical specimen. The papillary lesions that were found to be malignant were both discrete opacities on mammograms, it is of note that the non-comedo DCIS after excision was identified as a papillary lesion after VALCS biopsy, and the intraduct papillary carcinoma was initially picked up on FNA.

CNB guided by ultrasound was the only method in which no borderline lesions were subsequently found to be malignant. Surgical biopsy done on borderline lesions identified on cytological assessment after FNB showed $10 \%$ to be malignant. These are not unexpected findings as the majority of lesions biopsied by VALCS were calcifications compared to the lesions biopsied by FNB and $\mathrm{CNB}$ which were more likely to be mammographic and/ or sonographic densities. Almost one third of borderline lesions identified by VALCS were eventually diagnosed with a breast malignancy. Borderline lesions may coexist 
with and be difficult to distinguish from malignant lesions $[2,3]$. It is for this reason that a high index of suspicion for co-existing malignant disease should be entertained and that surgical excision should be undertaken to exclude such. This study also looked at identifying further criteria that might indicate which borderline lesions were more likely to be diagnosed as a malignancy. Our results and other studies have reported variable findings on mammography and ultrasound $[3,14,23,24]$.

\section{Conclusions}

The strength of this study comes from the relatively large sample of borderline lesions over a period of more than eight years. The main limitation is the small numbers of each type of lesion. With the exception of ADH, borderline lesions are rare findings.

This is a study of a screening population; hence the data is not confounded by clinical findings that may contribute to the decision for surgical excision. A multicentre study is recommended to increase the sample size in order to enable further review of the less common lesions. Also, this study did not look at long term follow up of these women; further research could contribute more information about the longer term outcomes after a biopsy shows a borderline lesion.

Further research is required to determine whether characteristics of the mammographic lesion (particularly calcification patterns), the area targeted for biopsy and number of core samples retrieved, can indicate a closer correlation with eventual pathology. In the present study, there were only a small number of malignancies associated with a significant family history and subsequent increased risk of breast cancer. As a result it should not influence the approach taken to borderline lesions in a breast screening program.

In conclusion, although surgical biopsies are invasive procedures with associated risk, they remain an important part of the diagnostic process. We recommend that for diagnostic certainty, surgical biopsies should continue to be performed after a needle biopsy identifies a borderline lesion.

\section{Acknowledgements}

The authors would like to thank Dr Georges Hazan and Dr John Buckingham for their helpful comments, Mr. Philip Crawford and Mr. Todd Hennessy for their help in accessing the patient files and staff at BreastScreen ACT\&SENSW for their hospitality.

\section{Author details}

${ }^{1}$ Australian National University, Medical School. The Canberra Hospital, Building 4, PO Box 11, Woden, ACT, 2606, Australia. ${ }^{2}$ BreastScreen ACT\&SENSW. 1 Moore Street, Canberra, ACT, 0200, Australia. ${ }^{3}$ The Canberra Hospital, Woden, ACT, 2606, Australia.

\section{Authors' contributions}

KMF and $\mathrm{AMB}$ conceived and designed the study. KMF completed the ethics application, provided academic input and coordination of the study and manuscripts. JJF carried out the data collection and analysis and later drafted the manuscript. AMB provided onsite supervision, quality control and interpretation of Breastscreen records. SJ double read the pathology slides and gave input to the manuscript from a pathology perspective. All authors read and approved the final manuscript.

\section{Authors' information}

KMF has been a breast physician since 1989 and is a Fellow of the Australasian Society of Breast Physicians. AMB is the Clinical Director of the regional breast screen program in the study and was able to provide on site guidance to JJF, who completed much of the initial work as part of a medical student research project for the Australian National University.

\section{Competing interests}

AMB is employed as the Clinical Director of Breastscreen ACT\&SENSW. The organization is not financing this manuscript.

Received: 5 May 2010 Accepted: 8 September 2010

Published: 8 September 2010

\section{References}

1. Australian Institute of Health and Welfare: BreastScreen Australia Monitoring Report 2002-2003 Canberra, ACT, Australia: AlHW 2006.

2. Jacobs TW, Connolly JL, Schnitt SJ: Nonmalignant lesions in breast core needle biopsies: to excise or not to excise? Am J Surg Pathol 2002, 26:1095-110

3. Houssami N, Ciatto S, Bilous M, Vezzosi V, Bianchi S: Borderline breast core needle histology: predictive values for malignancy in lesions of uncertain malignant potential (B3). Br J Cancer 2007, 96:1253-7.

4. Harvey JM, Sterrett GF, Frost FA: Atypical ductal hyperplasia and atypia of uncertain significance in core biopsies from mammographically detected lesions: correlation with excision diagnosis. Pathology 2002, 34:410-6.

5. Elsheikh TM, Silverman JF: Follow-up surgical excision is indicated when breast core needle biopsies show atypical lobular hyperplasia or lobular carcinoma in situ: a correlative study of 33 patients with review of the literature. Am J Surg Pathol 2005, 29:534-43.

6. Schnitt SJ, Vincent-Salomon A: Columnar cell lesions of the breast. Adv Anat Pathol 2003, 10:113-24.

7. Carder PJ, Murphy CE, Liston JC: Surgical excision is warranted following a core biopsy diagnosis of mucocoele-like lesion of the breast. Histopathology 2004, 45:148-54.

8. Dillon MF, McDermott EW, Hill AD, O'Doherty A, O'Higgins N, Quinn CM: Predictive value of breast lesions of "uncertain malignant potential" and "suspicious for malignancy" determined by needle core biopsy. Ann Surg Oncol 2007, 14:704-11.

9. iSource, National Breast Cancer Centre: Advice about familial aspects of breast cancer and ovarian cancer: A guide for health professionals Woolloomooloo: iSource NBCC 2000.

10. Irwig L, Macaskill P: Evidence relevant to guidelines for the investigation of breast symptoms Wolloomooloo, NSW: NBCC 1997.

11. Margenthaler JA, Duke D, Monsees BS, Barton PT, Clark C, Dietz JR: Correlation between core biopsy and excisional biopsy in breast highrisk lesions. Am J Surg 2006, 192:534-7.

12. Burak WE, Owens KE, Tighe MB, Kemp L, Dinges SA, Hitchcock CL, Olsen J: Vacuum-assisted stereotactic breast biopsy: histologic underestimation of malignant lesions. Arch Surg 2000, 135:700-3.

13. Jackman RJ, Nowels KW, Rodriguez-Soto J, Marzoni FA Jr, Finkelstein SI, Shepard MJ: Stereotactic, automated, large-core needle biopsy of nonpalpable breast lesions: false-negative and histologic underestimation rates after long-term follow-up. Radiology 1999, 210:799-805

14. Foster MC, Helvie MA, Gregory NE, Rebner M, Nees AV, Paramagul C: Lobular carcinoma in situ or atypical lobular hyperplasia at core-needle biopsy: is excisional biopsy necessary? Radiology 2004, 231:813-9.

15. Kunju LP, Kleer CG: Significance of flat epithelial atypia on mammotome core needle biopsy: Should it be excised? Hum Pathol 2007, 38:35-41. 
16. Brogi $E$, Tan L: Findings at excisional biopsy (EBX) performed after identification of columnar cell change (CCC) of ductal epithelium in breast core biopsy (CBX). [Meeting abstract] Mod Pathol 2002, 29-30.

17. Abdel-Fatah TM, Powe DG, Hodi Z, Lee AH, Reis-Filho JS, Ellis IO: High frequency of coexistence of columnar cell lesions, lobular neoplasia, and low grade ductal carcinoma in situ with invasive tubular carcinoma and invasive lobular carcinoma. Am J Surg Pathol 2007, 31:417-26.

18. Collins LC, Baer HJ, Tamimi RM, Connolly JL, Colditz GA, Schnitt SJ: Magnitude and laterality of breast cancer risk according to histologic type of atypical hyperplasia: results from the Nurses' Health Study. Cancer 2007, 109:180-7.

19. Doyle EM, Banville N, Quinn CM, Flanagan F, O'Doherty A, Hill AD, Kerin MJ, Fitzpatrick P, Kennedy M: Radial scars/complex sclerosing lesions and malignancy in a screening programme: incidence and histological features revisited. Histopathology 2007, 50:607-14.

20. Cawson JN, Malara F, Kavanagh A, Hill P, Balasubramanium G, Henderson M: Fourteen-gauge needle core biopsy of mammographically evident radial scars: is excision necessary? Cancer 2003, 97:345-51

21. Jacobs TW, Byrne C, Colditz G, Connolly JL, Schnitt SJ: Radial scars in benign breast-biopsy specimens and the risk of breast cancer. N Engl J Med 1999, 340:430-6.

22. Ali-Fehmi R, Carolin K, Wallis T, Visscher DW: Clinicopathologic analysis of breast lesions associated with multiple papillomas. Hum Pathol 2003, 34:234-9.

23. Mahoney MC, Robinson-Smith TM, Shaughnessy EA: Lobular neoplasia at 11-gauge vacuum-assisted stereotactic biopsy: correlation with surgical excisional biopsy and mammographic follow-up. AJR Am J Roentgenol 2006, 187:949-54.

24. Schreer I, Luttges J: Precursor lesions of invasive breast cancer. Eur J Radiol 2005, 54:62-71.

doi:10.1186/1477-7819-8-78

Cite this article as: Flegg et al: Surgical outcomes of borderline breast lesions detected by needle biopsy in a breast screening program. World Journal of Surgical Oncology 2010 8:78.

\section{Submit your next manuscript to BioMed Central and take full advantage of:}

- Convenient online submission

- Thorough peer review

- No space constraints or color figure charges

- Immediate publication on acceptance

- Inclusion in PubMed, CAS, Scopus and Google Scholar

- Research which is freely available for redistribution 